\title{
Erectile Dysfunction: Prevalence, Characteristics and Etiological Factors Among Urology Outpatients in Burkina Faso
}

\author{
Fasnéwindé Aristide Kaboré, Boureima Ouédraogo, Bienvenue Désiré Ky, \\ Clotaire Alexis Marie Kiemdiba Donega Yameogo, Brahima Kirakoya, Kambou Timothée
}

Department of Urology, University of Ouagadougou, Ouagadougou, Burkina Faso

\section{Email address:}

kaborefamd@icloud.com (F. A. Kaboré), boureims@gmail.com (B. Ouédraogo), yameogoclotaire@yahoo.fr (C. A. M. K. D. Yameogo), kobrahi@yahoo.fr (B. Kirakoya), timothee.kambou@gmail.com (K. Timothée)

\section{To cite this article:}

Fasnéwindé Aristide Kaboré, Boureima Ouédraogo, Bienvenue Désiré Ky, Clotaire Alexis Marie Kiemdiba Donega Yameogo, Brahima Kirakoya, Kambou Timothée. Erectile Dysfunction: Prevalence, Characteristics and Etiological Factors Among Urology Outpatients in Burkina Faso. International Journal of Clinical Urology. Vol. 2, No. 1, 2018, pp. 15-19. doi: 10.11648/j.ijcu.20180201.13

Received: June 17, 2018; Accepted: July 20, 2018; Published: August 24, 2018

\begin{abstract}
The erectile dysfunction (ED) is the inability to get or maintain an erection for a satisfied intercourse. This can affect the patient's life with an impact on his partner life and their relationship. We had conducted a transversal descriptive and analytical study based on prospective data's during a period of six month time (January 1st to June 30th). The sample population were Yalgado Ouedraogo University medical center male outpatient aged 18 year and up from the urologyandrology department. The evaluation of the ED was done by using a self survey form of the International Index of the Erectile Function simplified in five questions (IIEF5). A total of 440 patients, 410 had and exploited survey. The average age of the included patients was $52.4+/-14.1$ (the extremes were 24 and 68 years old). 111 patients had an ED with a prevalence of $27 \%$. The average age who had an ED was $48.2+/-11.9$ years old. The ED by age prevalence showed an progressive increase with age. The ED is frequent in our hospital urology department. This concerns almost $1 / 3$ of our department patients. Its occurence and severity are influenced by its length, the age, the smokes, the obesity, the cardiovascular diseases, and the SBAU.
\end{abstract}

Keywords: Erectile Dysfunction, Sexual Dysfunction, Prevalence

\section{Introduction}

The erectile dysfunction (ED) is the inability to get or maintain an erction for a satisfied intercourse. This can affect the patient's life with an impact on his partner life and their relationship. [1].

The real prevalence of the ED is unknown cause the problem is sometime a taboo and the evaluation methods are different from study. Ayta [2] in a multinational study based on the general population had estimated in 1999 at nearly 322 millions the number of men that would have an ED in 2025. In France the prevalence of ED will be $31.6 \%$ [3] against $35 \%$ in the USA [4]. In Africa the prevalence of the ED has been evaluated at $46 \%$ in Senegal [5], 32.9\% in Morroco [6]. In Burkina Faso the prevalence of the ED had been evaluated at $57 \%$ among diabetic [7].

No study in our knowledge had been conducted to evaluate the prevalence of ED in urological area in Burkina Faso.
The purpose of our study was to evaluate the prevalence of ED and its severity among urology patients and to identify the ED etiologics factors in urology -andrology department of the Yalgado Ouedraogo University Medical Center.

\section{Methods}

We had conducted a transversal descriptive and analytical study based on prospective data's during a period of six month time (January 1st to June 30th). The sample population were Yalgado Ouedraogo University medical center male outpatient aged 18 year and up from the urologyandrology department.

All the patient must give their clear consensus verbally before their inclusion in the study. The non inclusion criteria was to reject the participation at the study. Considering 520 
patients, 440 patients did accept to participate at the study; approximately a value $84.6 \%$.

The databases were collected from a standard questions. Our studied area were:

Socio demographics: ages, statuses, level of education, and occupation.

Clinics: the ED characteristics (types, installations modes, the lasting time) the sides effects associated (effect on the libido, ejaculations problems), painful intercourse and the impact on life's quality.

Etiological: Tabac and alcohol consumption, the diabete, the obesity (the body mass index $>30 \mathrm{~kg} / \mathrm{m} 2$ ), the high blood pressure, the cardiovascular diseases, the neurological diseases, and others comorbidities.

The evaluation of the ED was done by using a self survey form of the International Index of the Erectile Function simplified in five questions (IIEF5) Rosen [8]. The patients who had an ED (IIEF5 less or equal to 20) were classified in three groups: the severe ED with an IIEF5 scored between 5 and 10, the moderate ED with an IIEF5 scored between 11 and 15, the low ED with an IIEF5 scored between 16 and 20. The scores that were less than 5 weren't take in consideration. All the patients diagnosed with an ED had a full clinical test including the fasting glucose test, the lipids screen, the total testosterone level in the morning (between 7 and $8 \mathrm{am}$ ), and the realisation of electrocardiogram.

The impact of the patient's life qualities was evaluated by these following question:

If you should spend the rest of your lifetime with your actual sexual trouble, that will be? «moderately supportable», «supportable», «insupportable», «difficult to support» «insupportable at all».

The databases received were taped and analyzed with a 2008 SPSS (Statistical Package for Social Science) logiciel, version's 17.00 Chicago. SPSS inc. The results were presented in term of frequencies, mean, standard deviation for the quantitative variables and in percentage for the qualitative variables. The bivariate analysis using the Khi2 test square brut of Person were used to evaluate the correlation between qualitative variables. The statistical level of signification "P" has been fixed at 0.05. A multivariate analysis (logistics regression) has been used to evaluate the correlation between the etiological different factors of the ED (odd ratios, the confidence interval 95\%,). The statistical significant level $\mathrm{p}=0.05$ were used.

\section{Results}

A total of 440 patients, 410 had and exploited survey. The average age of the included patients was $52.4+/-14.1$ (the extremes were 24 and 68 years old). One hundred and eleven patients had an ED with a prevalence of $27 \%$. The average age who had an ED was $48.2+/-11.9$ years old. The ED by age prevalence showed an progressive increase with age. [Table 1]
Table 1. IIEF5 score by age.

\begin{tabular}{llllll}
\hline & & \multicolumn{2}{l}{ Score IIEF } & \multirow{2}{*}{ Total } \\
\cline { 3 - 5 } & & $\mathbf{5 - 1 0}$ & $\mathbf{1 1 - 1 5}$ & $\mathbf{1 6 - 2 0}$ & \\
\hline \multirow{4}{*}{ Age } & {$[18-30]$} & 1 & 2 & 5 & 8 \\
& {$[30-40]$} & 2 & 7 & 11 & 20 \\
& {$[40-50]$} & 3 & 15 & 7 & 25 \\
\multirow{3}{*}{ Total } & {$[50-60]$} & 8 & 26 & 2 & 36 \\
& {$[60-70]$} & 15 & 7 & 0 & 22 \\
\hline
\end{tabular}

The average time of ED prevalence before any medical consultation was 2.7 year and 1.8 year, the extremes used were 3 months and 8 years old. Most of the patients $(86.5 \%$, $\mathrm{n}=96$ ) were consulting a year after the beginning of the ED. The consultation time limit was strongly correlated when a severe ED happened $(\mathrm{p}=0.0001)$. Eighty five patients $(85.6 \%)$ were ashamed to talk about their feelings to their doctor. The reasons for consultation were dominated by the low urinary symptoms. [Table 2].

Table 2. Distribution of patients according to the reason for consultation $(n=111)$.

\begin{tabular}{lll}
\hline Reason for consultation & Effective & Percentage \\
\hline Checkup & 35 & $31.5 \%$ \\
Symptoms of lower urinary tract & 39 & $35.1 \%$ \\
urolithiasis & 7 & $6.3 \%$ \\
Infertility & 2 & $1.8 \%$ \\
testicular pain & 1 & $0.9 \%$ \\
anejaculation & 1 & $0.9 \%$ \\
erectile dysfunction & 15 & $13.5 \%$ \\
Peyronie's Disease & 2 & $1.8 \%$ \\
hematuria & 4 & $3.7 \%$ \\
premature ejaculation & 5 & $4.5 \%$ \\
\hline
\end{tabular}

Hundred and ten patients had a secondary ED (99.1\%). The ED was low among 25 patients (21.6\%), medium among 57 patients (51.4\%), and severe among 29 patients $(27 \%)$. The ED was progressively installed on 106 patients $(80.2 \%)$, it was very lowered on 21 patients (19.1\%). The ejaculations troubles were associated among 71 patients $(64 \%)$. It was an early ejaculations in 47 cases $(66.2 \%)$, late in 2 cases $(2.8 \%)$, hard in 8 cases $(11.3 \%)$, and 14 cases of anejeculation (19.7\%). The most common comorbidities were: dyslipidemia $(n=61,54.9 \%)$, high blood pressure $(n=18$, $16.2 \%)$, and the diabetes $(n=15.13 .5 \%)$ [Table 3$]$.

Table 3. Characteristics of patients who had ED $(n=111)$.

\begin{tabular}{lll}
\hline Characteristics & Nomber (n) & Fréquency (\%) \\
\hline Age & 8 & \\
{$[18-30]$} & 20 & $7.2 \%$ \\
{$[30-40]$} & 25 & $18 \%$ \\
{$[40-50]$} & 36 & $22.5 \%$ \\
{$[50-60]$} & 22 & $32.4 \%$ \\
{$[60-70]$} & & $19.8 \%$ \\
marital status & 76 & \\
Married & 27 & $68.5 \%$ \\
Single & 8 & $24.3 \%$ \\
Widower & & $7.2 \%$ \\
Study level & 16 & \\
No schooling & 21 & $14.4 \%$ \\
Primary & 41 & $18.9 \%$ \\
Secondary & & $37.9 \%$ \\
\hline
\end{tabular}




\begin{tabular}{lll}
\hline Characteristics & Nomber $(\mathbf{n})$ & Fréquency $\mathbf{( \% )}$ \\
\hline $\begin{array}{l}\text { university } \\
\text { professional activity }\end{array}$ & 33 & $29.7 \%$ \\
yes & 80 & $72 \%$ \\
No & 31 & $28 \%$ \\
HTA & & \\
Yes & 18 & $16.2 \%$ \\
No & 93 & $83.8 \%$ \\
Diabetes & & \\
Yes & 15 & $13.5 \%$ \\
No & 96 & $86.5 \%$ \\
Alcohol & & \\
Yes & 47 & $43.3 \%$ \\
No & 64 & $56.7 \%$ \\
Tobacco & & \\
Yes & 29 & $26.1 \%$ \\
No & 82 & $73.9 \%$ \\
Dyslipidemia & & \\
Yes & 61 & $54.9 \%$ \\
No & 50 & $45.1 \%$ \\
IMC & & \\
$<30 \mathrm{~kg} / \mathrm{m} 2$ & 80 & $72 \%$ \\
$>30 \mathrm{~kg} / \mathrm{m} 2$ & 31 & $28 \%$ \\
ECG abnormalities & & $45 \%$ \\
Yes & 50 & $55 \%$ \\
No & 61 & \\
\hline
\end{tabular}

The most frequent anomalies at the ECG were the the hypertrophy of the left auricular and ventricular with respectively $14.4 \%(n=16)$ and $11.7 \%(n=13)$. The existence of an anomaly at the ECG was significantly correlated at an ED start $(p=0.04 \%)$ [Table 4].

Table 4. IIEF5 score based on the results of ECG.

\begin{tabular}{llll}
\hline \multirow{2}{*}{ Results ECG } & \multicolumn{3}{l}{ SCORE IIEF-5 Effective (\%) } \\
\cline { 2 - 4 } & $\mathbf{5 - 1 0}$ & $\mathbf{1 1 - 1 5}$ & $\mathbf{1 6 - 2 0}$ \\
\hline Left Ventricular Hypertroph & $7(43.7 \%)$ & $9(56.3 \%)$ & $0(0 \%)$ \\
Hypertrophy Atrium G & $6(46.2 \%)$ & $7(53.8 \%)$ & $0(0 \%)$ \\
myocardial infarction & $5(50 \%)$ & $4(40 \%)$ & $1(10 \%)$ \\
Atrio Ventricular block type I & $3(75 \%)$ & $1(25 \%)$ & $0(0 \%)$ \\
Hypertrophy Left Heart & $3(60 \%)$ & $2(40 \%)$ & $0(0 \%)$ \\
Right Ventricle Hypertrophy & $1(50 \%)$ & $1(50 \%)$ & $0(0 \%)$ \\
Normal & $4(8 \%)$ & $25(50 \%)$ & $22(44 \%)$ \\
TOTAL & $25(50 \%)$ & $24(48 \%)$ & $1(2 \%)$ \\
\hline
\end{tabular}

Only 7 patients declared their life's supportable with their ED. [Table 5].

Table 5. Impact of ED on the quality of life.

\begin{tabular}{|c|c|c|c|c|c|}
\hline \multirow[b]{2}{*}{ Score IIEF-5 } & \multicolumn{5}{|l|}{ quality of life } \\
\hline & $\begin{array}{l}\text { Insupportable at all } \\
(\mathrm{n} / \%)\end{array}$ & $\begin{array}{l}\text { Insupportable } \\
(\mathrm{n} / \%)\end{array}$ & $\begin{array}{l}\text { difficult to support } \\
(\mathrm{n} / \%)\end{array}$ & $\begin{array}{l}\text { moderately supportable } \\
(\mathrm{n} / \%)\end{array}$ & $\begin{array}{l}\text { Supportable } \\
(\mathbf{n} / \%)\end{array}$ \\
\hline $16-20$ & $2 / 1.8$ & $0 / 0$ & $12 / 10.8$ & $11 / 9.9$ & $5 / 4.5$ \\
\hline $11-15$ & $3 / 2.7$ & $12 / 10.9$ & $31 / 27.9$ & $9 / 8.1$ & $2 / 1.8$ \\
\hline $5-10$ & $9 / 8.1$ & $4 / 3.6$ & $6 / 5.4$ & $5 / 4.5$ & $0 / 0$ \\
\hline Total & $14 / 12.6$ & $16 / 14.5$ & $49 / 44.1$ & $25 / 22.5$ & $7 / 6.3$ \\
\hline
\end{tabular}

The ED prevalence by age tranches revealed and progressive augmentation with age from $8 \%$ between $18-30$ years old to $36 \%$ between 50-60years old. Age was significantly associated when ED occurred. The hypotestosteronemia, the sedentary lifestyle, the decrease of the libido were the most risk factors at the multivariate analysis. [Table 6].

Table 6. Multivariate analysis of risk factors associated with ED.

\begin{tabular}{|c|c|c|c|c|}
\hline Risk factors & $\mathrm{N} / \%$ & $\mathbf{P}$ & ODDS Ratio (IC 95\%) & Significatif Yes/No \\
\hline HTA & $18 / 16.2$ & 0.02 & $3.3(0.9-12.2)$ & Yes \\
\hline Diabetes & $15 / 13.5$ & 0.07 & $4.6(0.9-37.4)$ & Yes \\
\hline Age $\geq 40$ years & $83 / 74.8$ & 0.001 & $3.5(2.1-6.1)$ & Yes \\
\hline sedentary lifestyle & $84 / 75.8$ & 0.01 & $4.3(1.6-11.4)$ & Yes \\
\hline Hypotestostéronémie & $14 / 12.6$ & 0.002 & $6.5(3.3-20.6)$ & Yes \\
\hline Decreased libido & $21 / 18.9$ & 0.0001 & $6.2(2.8-15.4)$ & Yes \\
\hline Obesity $\mathrm{BMI}>30$ & $31 / 27.9$ & 0.07 & $1.2(0.5-3.6)$ & No \\
\hline Alcohol & $47 / 43.3$ & 0.1 & $0.8(0.3-2.2)$ & No \\
\hline Tobacco & $29 / 26.1$ & 0.8 & $0.7(0.8-3.4)$ & No \\
\hline
\end{tabular}

\section{Discussion}

The ED is the most known sexual dysfunction, many studies interested in his epidemiological aspect, clinical and also therapeutic $[1,2]$. Our prevalence was considerably inferior than that of Leye (46\%) in Senegal [5], Baka (32.9\%) in Morocco [6] and Nordin (81.5\%) in Malaysia. A low prevalence of $20 \%$ was mentioned by many authors [10-12]. The big disparity of these results makes their comparison difficult because of the sample size, the target population, and the ED evaluation strategies were different from one study to another one. Many questioners exist but the IIEF was the most valid reproducible. it was an object to a complete psychometric evaluation and help to evaluate the erectile function and also the sexual desire [8].

The ED prevalence by age had revealed a progressive augmentation with the age going from $8 \%$ between $18-30$ to $36 \%$ between $50-60$ years. The distribution of the severity of ED by age group varies according to the authors. leye [5] and 
Dougherty [13] have found a statistically significant and steady increase of ED with age and increases in severity with age. This relation between the age and the ED could be explained by the comorbidies existence on older ages and the oxidative saged stresses that could cause an nervous and endothelial degeneracy on the elements that help the erections mechanism.

The average consultation period was 2.7 years and most of the patients had consulted one year after the beginning of the symptomatologic. In our context in Africa, the recourse at the traditional medicines more easy to access could explain the late consultation. The occurrence of ED is influenced by the level of education [14].

It is more and more acceptable that the ED and the cardiovascular diseases are intimately reliable and that the erection troubles would be an early stage of cardiovascular diseases. according to Fang[15]. The ED and the cardiovascular diseases have the same physiopathology creating some endothelial anomalies. The cardiovascular risks factors would also be the ED risks factors. The database of our study corroborate those physiopathologics assertions. The sedentary lifestyle, the alcoholism, the smoking which are some cardiovascular risks factors were strongly correlated to the ED. The high blood pressure was significantly associated at the ED severity. The high blood pressure is the most frequent vascular disease. In our study the ED's risk on high blood pressure patients was 3.3 times more elevated than patients without it. Some others researches $[4,15,16]$ were indicated that the high blood pressure being one of the main risk factors explained the high correlation between it and the ED.

The ED prevalence among diabetics was $13.5 \%$ in our series of study. The ED risks on diabetics was $4.6 \%$ more elevated. this result is in accepting the literature databases which showed a high ED prevalence in diabetics population. This prevalenceare not stable from $20 \%$ to $90 \%$ according to publish. [5, 17]. Leye and al. showed a correlation between the start of the ED and the evolution times of the diabetes but couldn't find any difference in the starting of the ED according to the type of diabetes [5]. For other authors the ED will be more frequent on type 1 diabetes than type 2 one, and this difference could be persistent after the age effect correction [9]. The development of the erectile disorders on diabetics patients are the consequences of many mechanism acting between themselves: vascular problems, endothelial dysfunction, neuropathies, hormones disorders, and psychological troubles in a chronic disease case. [17].

Rimtebaye and al. did notice that the level of ED increased with the smoking intoxication time but there was no correlation with the ED severity [18]. The smoking sid effects on the erectile function are revealed by many authors and were incriminating many mechanism: the inability of the muscular fibers function, the blood hyper coagulability, the fatty acids liberation, and the catecholamines and also a direct toxic action of nicotine on vascular endothelium. [3, 19, 20].

The alcohol influence on erection was cited in the literature. The correlation between alcoholism and ED has been reported by many authors [21]. However, we did not find any correlation between alcohol consumption and the start of the ED

The SBAU were dominated in consultant reasons in our study. This could be related to an selection biases cause the sample population studied was constituted by outpatients received in urology. Among this biases, many authors reported a significant relation between the SBAU and the ED $[6,14,22]$. Baka \& al [6] 2000 reported in their researches $72.2 \%$ of lower urinary tract on ED patients against $37.7 \%$ on none ED patients. The link between SBAU and ED stay incompletely clear. The prostatic pathology and others comorbidities (diabetes, high blood pressure) most present among older patients were seen as etiological factors. Researches are necessary to have a good understanding on the relation between underlying pathologies and the ED in order to prevent the happening of ED on SBAU patients.

\section{Conclusion}

The ED is frequent in our hospital urology department. This concerns almost $1 / 3$ of our department patients. Its occurence and severity are influenced by its length, the age, the smokes, the obesity, the cardiovascular diseases, and the SBAU. The patients were ashamed to talk about the subject to their doctor where the importance to give them a good understanding of the ED. The ED impact on patients life qualities were important. Our results advise that a search of ED should be systematic for all urology consultants patients and inform and educate the population.

\section{References}

[1] MH Colson, B Cuzin, A Faix, L Grellet, E Huyghes. Erectile dysfunction, twenty years after. Sexolog. 2018;27:2-8.

[2] M Quilter, L Hodges, PV Hurst, B Borman. Male Sexual Function in New Zealand: A Population-Based CrossSectionnal Survey of the Prevalence of Erectile Dysfunction in Men aged 40-70 Years. J of Sex M. 2017;14(7):928-36.

[3] F Giuliano, M Chevret- Measson, A Tsatsaris, C Reitz, M Murino, P Thonneau. Prévalence de l'insuffisance érectile en FRANCE: résultats d'une enquête épidémiologique menée auprès d'un échantillon représentatif de 1004 hommes. Prog Urol. 2002; 12(2):260-67.

[4] AL Burnett, A Nehra, RH Breau, DJ Culkin, MM Faraday, LS Hakim, JHeidelbaugh, M Khera, Kevin T, MM Minier, CJ Nelson, HS Nejad, AD Seftel, AW Shindel. Erectile dysfunction: AUA Guideline. J Urol. 2018;200:1-9.

[5] MMM Leye, P Ndiaye, CT Diop, NM Thiam, DF Fall, O Ka et al. Etude de prévalence et des caractéristiques sociodémographiques, cliniques associées au dysfonctionnement érectile en milieu hospitalier dans la région de Dakar (Sénégal). Uro Andro. 2015; 3(1): 138-44.

[6] KH Baka, SM Moudouni, G Sanda, B Sadiki, AM Lakmichi, Z Dahami, I Sarf. Prevalence of Erectile Dysfunction in Urology. Af J Urol. 2017; 23:327-330. 
[7] T Kambou, C Zaré, AK Paré, A Ouattara, YL Somé, BG Sanon. Erectile dysfunction among diabetic men in two medical centers in Burkina Faso: Epidemiological, diagnosis and therapeutic aspects. Ad Sex Med. 2014;4:1-5.

[8] RC Rosen, JC Cappelleri and N Gendrano. The International Index of Erectile Function (IIEF): a state-of-the-science review. Int J impot Res. 2002; 14 (4):226-44.

[9] RB Nordin, T Soni, A Kaur, KP Loh, S Miranda. Prevalence and predictors of erectile dysfunction in adult male outpatient clinic attendees in Johor, Malaysia. Singapore Med J. 2018;123.

[10] AP Bouya, AWS Odzebe, MR Mayala, AAM Ondongo, N Andzouana, HG Monabeka. La dysfonction érectile au Congo: premières données sur la fréquence de ce motif de consultation et profil clinique au centre hospitalier universitaire de Brazzaville. Androl. 2012; 22 (2):92-5.

[11] DG Yovwin, FA Imarhiagbe, EM Obazee, TC Oguike. Erectile dysfunction in a sub-saharan African population: Profile and correlates in a tertiary care hospital. Sah Med J. 2015; 18(3):121-25.

[12] MN Salama, AA Eid, A Hatem, AK Swidan. Prevalence of erectile dysfunction in Egyptian males with metabolic syndrome. Aging Male. 2018;19:1-7.

[13] Patrick Dougherty. Erectile Dysfunction. Physician Assist Clin 2018, 3:113-127.

[14] Y Diallo, R Kane, SC Kouka, B Fall, C Ze Ondo, A Ndiaye, A Phiri, AS Soumah, B Diao. Erectile Dysfunction: Clinical and Epidemiological Aspects in Senegal. Open J Urol. 2015; 5:147-54.
[15] SC Fang, RC Rosen, JA Vita, P Ganz, V Kupelian. Changes in erectile dysfunction over time in relation to Framingham cardiovascular risk in the Boston Area Community Health (BACH) Survey. J Sex Med. 2015;12(1):100-108.

[16] C Vlachopoulos, N Ioakeimidis, C Stefanadis. Biomarkers, erectile dysfunction, and cardiovascular risk prediction: the latest of an evolving concept; Asian J Androl. 2015. 17(1):1720 .

[17] M Sondhi, A Kakar, A Gogia, M Gupta. Prevalence of erectile dysfunction in diabetic patients. Curr M Res Pract. 2018;8:8891.

[18] CKK Rimtebaye, EM Mpah, AA Zarif, FA Sillong, M Kaboro. Profile of patient presenting with erectile dysfunction. Uro Andro. 2018;1(9):438-44.

[19] MG Biebel, AL Burnett and H Sadeghi-Nejad. Male Sexual Function and Smoking. Sex Med Rev. 2016;4(4):366-375.

[20] I Scarneciu, S Lupu, CC Scarneciu. Smoking as a risk factor for the development of Erectile Dysfunction and Infertility in Men; evaluation depending on the anxiety levels of these patients. Pro Soc Beha Sc. 2014;127: 437-42.

[21] DK Prabhakaran, A Nisha and PJ Varghese. Prevalence and correlates of sexual dysfunction in male patients with alcohol dependence syndrome: A cross-sectional study. Indian J Psychiatry. 2018;60(1):71-77.

[22] C De Nunzio, CG Roehrborn, KE Andersson, KT McVary. Erectile Dysfunction and Lower Urinary Tract Symptoms. Eur Urol. 2017;3(4-5):352-363. 